\title{
Inversão gravimétrica 3D de corpos máficos-ultramáficos portadores de minério de cobre no norte da Bahia
}

\author{
Robson Santos da Purificação* (IGEO/UFBA), Daniel Conceição dos Santos (IGEO/UFBA), Florivaldo Oliveira Sena
} (SERVIGEO) e Marcos Alberto Rodrigues Vasconcelos (IGEO/UFBA)

Copyright 2016, SBGf - Sociedade Brasileira de Geofísica

Este texto foi preparado para a apresentação no VII Simpósio Brasileiro de Geofísica, Ouro Preto, 25 a 27 de outubro de 2016. Seu conteúdo foi revisado pelo Comitê Técnico do VII SimBGf, mas não necessariamente representa a opinião da SBGf ou de seus associados. É proibida a reprodução total ou parcial deste material para propósitos comerciais sem prévia autorização da SBGf.

\section{Abstract}

This paper proposes to analyze the application of the gravimetric method in copper ore prospecting in the Valley of Curaçá River in northern Bahia, Brazil. Was generated 3D inverse gravimetric model in order to verify the validity of the method in copper ore mining associated with mafic and ultramafic rocks. The inverse mathematical model was generated through the automatic iterative method with setting limits. Finally, ore levels earned in drill core were faced with vertical profiles of the inverse model in order to verify the applicability and consistency of the gravimetric method in mapping and modeling bodies associated with mineral occurrence.

\section{Introdução}

A região do Vale do Rio Curaçá na Bahia já é conhecida pela ocorrência de minério de cobre e em 2009 foi responsável por $12,1 \%$ da produção desse minério no Brasil (Farias, 2009), contribuindo para a manutenção da posição de $15^{\circ}$ maior produtor ocupada pelo país. A região está localizada na parte norte do Cráton do São Francisco que é definida por Barbosa (1997) como uma plataforma sin-Brasiliana de terrenos ArqueoProterozóicos.

O cobre é o principal metal não ferroso utilizado na indústria, principalmente devido à sua boa condutibilidade elétrica. A localização e mapeamento de reservas desse minério mostra-se estratégica no processo de desenvolvimento e industrialização de qualquer país.

$\mathrm{Na}$ região, a mineralização ocorre associada às rochas máficas e ultramáficas. Delgado e Souza (1975) afirmam que existem inúmeros corpos deste tipo potencialmente hospedeiros de mineralização associados e concordantes às rochas altamente metamorfizadas e migmatizadas da região.

Neste trabalho, os estudos concentraram-se sobre dois alvos da Fazenda Angico no município de Curaçá na Bahia. Os alvos são denominados como Cercado Velho CV e Lagoa da Mina - LM estão afastados aproximadamente 800 metros e foram identificados em superfície pela ocorrência de solo massapê escuro típico da alteração de rochas máficas. Os dados utilizados foram cedidos pela Mineração Caraíba S/A.

A gravimetria é um dos métodos geofísicos mais comumente utilizados na prospecção mineral, seja de forma direta na localização e delimitação de corpos de minérios maciços como os sulfetos, seja de forma indireta na localização de rochas hospedeiras. No caso dos alvos estudados espera-se obter uma boa resposta geofísica através da gravimetria principalmente devido ao fato de as rochas máficas e ultramáficas que são as rochas hospedeiras/associadas ao minério possuírem densidade superior às rochas encaixantes.

Neste sentido, o objetivo do presente trabalho consiste em efetuar uma análise à luz da resposta geofísica gravimétrica do comportamento dos depósitos em subsuperfície por serem conhecidamente mais densas que as rochas encaixantes. Para isso efetuou-se a inversão dos dados gravimétricos.

$\mathrm{Na}$ resolução do problema inverso supõe-se que a forma do corpo possa ser recuperada com boa precisão, desde que se estabeleça alguns parâmetros como limites, através de um modelo interpretativo que considera o contraste de densidade constante dentro das células retangulares justapostas. $O$ modelo inverso foi seccionado em perfis de direção Leste - Oeste e os dados foram confrontados com dados de testemunho de sondagem com o objetivo de validar a coerência do modelo.

\section{Metodologia}

Os dados gravimétricos utilizados foram coletados entre 2010 e 2012 com gravímetro diferencial. Os valores de anomalia Bouguer foram calculados utilizando os arquivos .xls disponibilizados por HOLOM et al. (2007). O mapa da anomalia Bouguer bem como a localização das linhas do levantamento gravimétrico estão dispostas na figura 1 .

$\mathrm{Na}$ resolução do problema inverso busca-se a obtenção de um modelo matemático cujas propriedades produzem anomalias tão próximas às medidas em campo e pode ser simplificada da seguinte forma:

$$
B=A p
$$

onde b é o vetor de medidas da anomalia Bouguer, A é a matriz da função de Green contendo a distribuição espacial do meio e p é o vetor das densidade, de maneira simples, resolver o problema inverso consiste em determinar os parâmetros geométricos e físicos da fonte, sendo:

$$
p=A^{*} b
$$


onde $A^{*}$ representa um operador matricial inverso adequado para a resolução do problema.

O problema inverso para o método gravimétrico é instável na presença de ruídos e não tem solução única (Castro, 2005). Algumas formas de reduzir a instabilidade do problema inverso é a adoção de vínculos físicos e geológicos aos procedimentos computacionais, como estabelecer limites inferiores e superiores para os parâmetros do modelo, concentração das fontes anômalas em torno de um elemento geométrico e compactação da fonte.

$\mathrm{Na}$ resolução do problema inverso supõe-se que a forma do corpo possa ser recuperada com boa precisão através de um modelo interpretativo que considera o contraste de densidade constante dentro das células retangulares justapostas.

A densidade média utilizada foi $2,67 \mathrm{~g} / \mathrm{cm}^{3}$. O modelo foi gerado com tamanho vertical de aproximadamente $600 \mathrm{~m}$ a altitude média da área de estudo é de $417 \mathrm{~m}$.

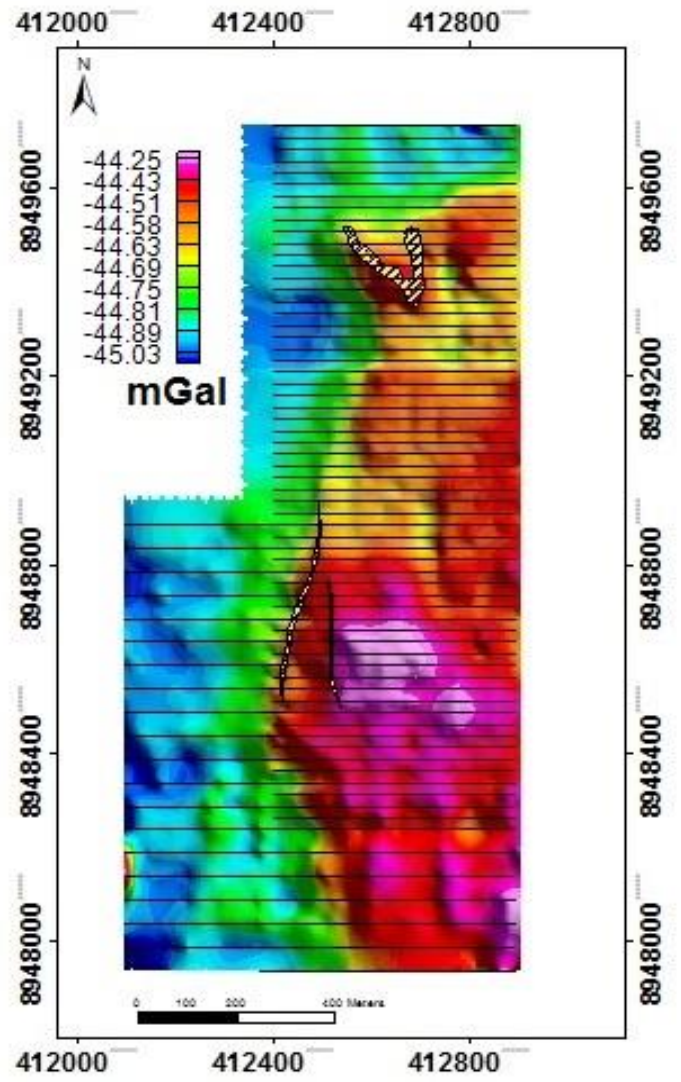

Figura 1 - Mapa da Anomalia Bouguer e disposição das linhas do levantamento gravimétrico. Os polígonos que sobrepõem os dados correspondem a representações esquemática dos corpos mineralizados..

Os dados foram processados em software comercial, gerando um modelo inverso tridimensional para visualização através de ferramentas interativas de objetos $3 D$, em seguida o modelo foi seccionado na direção leste oeste produzindo perfis do modelo em 2D que foram confrontados com dados de testemunhos de sondagem.

\section{Resultados}

O mapa da anomalia Bouguer (figura 1) apresenta os maiores valores localizados sobre os alvos, indicando a coerência do método e a ocorrência de corpos de maior densidade em subsuperfície.

O modelo matemático inverso foi disposto em forma geométrica regular, interpolado pelo método da mínima curvatura (figura 2) apresentando um modelo de células retangulares justapostas com contrastes de densidade.

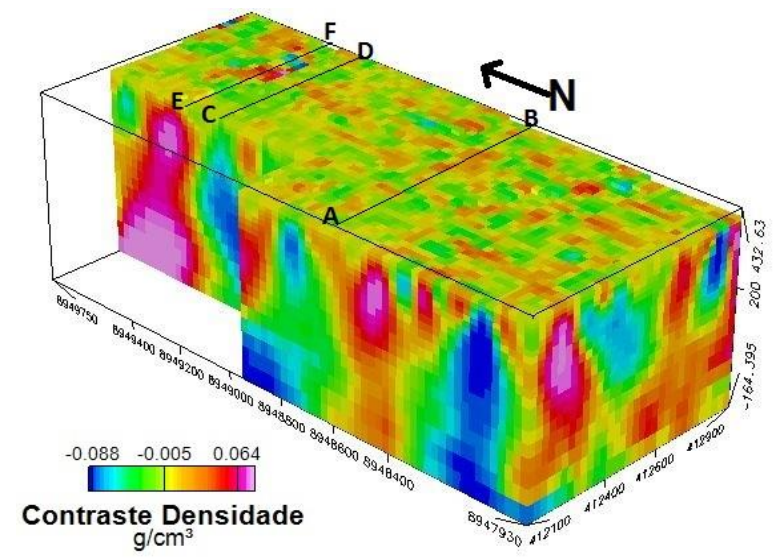

Figura 2- Modelo inverso dos dados gravimétricos com contrastes de densidades interpolados pelo método de mínima curvatura.

Carminatti (2006) na realização de trabalho para modelamento de corpos máficos-ultramáficos afirma que a gravimetria é um excelente método para mapeamento destes corpos, pois a densidade dos mesmos é conhecidamente alta gerando boa resposta geofísica em contraste com as rochas encaixantes.

O alvo Lagoa da Mina localizado na porção norte é constituído predominantemente por rochas noríticas e dioríticas com piroxenitos e anfibolitos associados. A morfologia do corpo é bem visível em campo devido ao solo massapê cinza escuro característico da alteração deste tipo de rocha (Delgado e Souza, 1975). Já o alvo Cercado velho na porção sul não é facilmente identificado pois os corpos máficos-ultramáficos apresentam-se em forma de lentes estreitas.

O modelo matemático inverso apresenta os maiores contrastes de densidade localizados nas posições dos alvos. Na porção norte o corpo mais denso do modelo ocorre de forma isolada denotando a ocorrência de apenas um corpo em subsuperfície. Na porção sul há a ocorrência de vários corpos de densidade elevada principalmente a leste do alvo Cercado Velho.

Neste trabalho serão apresentadas duas seções extraídas do modelo inverso, uma seção localizada na porção norte da área do levantamento e outra na porção sul, sobre os alvos Lagoa da Mina e Cercado Velho 
respectivamente. As seções foram plotadas em mapas cujo eixo vertical representa a profundidade. Também foram plotados sobre cada seção os teores de cobre auferidos nos testemunhos de sondagem com o objetivo de verificar se a ocorrência de mineralização coincide com as zonas com as zonas mais densas do modelo.

A seção vertical I (figura 3) foi extraída do modelo matemático inverso na posição $8948761 \mathrm{mN}$ sobre o alvo Cercado Velho. Nesta seção os testemunhos de sondagem indicaram a ocorrência de teores de cobre de até $2.5 \%$. A seção vertical evidencia a ocorrência de um corpo de maior densidade que as encaixantes localizado na entre as posições 412400 e 412800 Leste. O corpo mais denso parece dividir-se ao se aproximar da superfície, provavelmente essa característica estruturas tenha sido adquirida com os diversos processos de dobramentos e falhas ocorridos na região e já estudados por diversos autores como Delgado e Souza (1975), Sá (1981), D'el Rey Silva (1984) e Bello (1986).

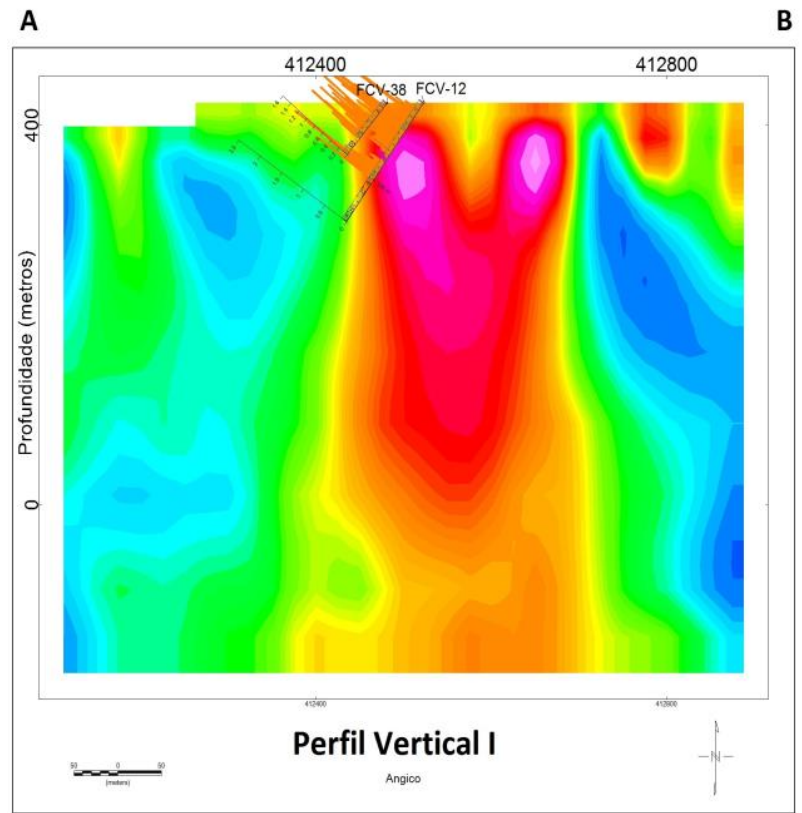

Figura 3: Perfil vertical do modelo gravimétrico inverso na posição $8948761 \mathrm{mN}$ correspondente ao perfil $A B$ no

bloco tridimensional da figura $2 \mathrm{com}$ a disposição esquemática dos furos FCV-12 e FCV-38 com dados de teor de cobre.

Os maiores teores de cobre parecem estarem associados às bordas dos corpos mais densos do modelo inverso os furos analisados na seção I foram FCV-12 e FCV-38 com $153 \mathrm{~m}$ e $70,80 \mathrm{~m}$ de profundidade respectivamente.

A seção vertical II (figura 4) foi extraída do modelo inverso na posição $8949361 \mathrm{mN}$ sobre o alvo Lagoa da Mina. É possível notar a ocorrência de apenas um corpo denso centralizado no perfil, localizado entre as posições 412500 e 412800 Leste, os maiores teores de cobre coincidem com as partes mais densas do modelo. Os teores de cobre nos furos FLM-43 e FLM-46 chegam a $2,5 \%$ e ocorrem predominantemente nas litologias piroxenito e melanorito rochas que apresentam densidades situadas entre 3,2 e $3,9 \mathrm{~g} / \mathrm{cm}^{3}$, maiores que a média da crosta terrestre que é de $2,67 \mathrm{~g} / \mathrm{cm}^{3}$.

C

D

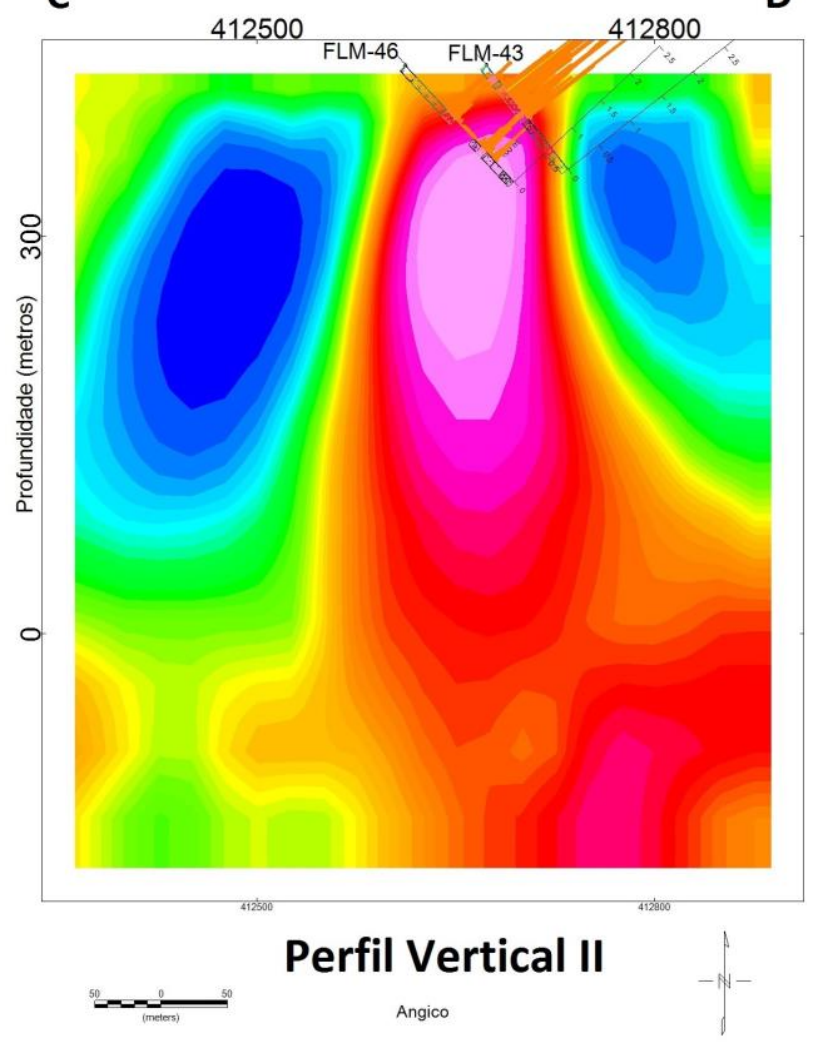

Figura 4: Perfil vertical do modelo gravimétrico inverso na posição $8949361 \mathrm{mN}$ correspondente ao perfil $C D$ no bloco tridimensional da figura $2 \mathrm{com}$ a disposição esquemática dos furos FLM-43 e FLM-46 com dados de teor de cobre

O comportamento da anomalia Bouguer nos perfis I e II é marcado por variações bastantes suaves da ordem de $0,4 \mathrm{mGal}$ as anomalias mais negativas situam-se sobre as rochas gnáissicas que predominam na geologia local, enquanto os maiores valores correm sobre os alvos de estudo deste trabalho.

\section{Discussão e Conclusões}

Delgado e Souza (1975) em um estudo sobre o potencial cuprífero do vale do Curaçá para o Departamento Nacional de Pesquisa Mineral - DNPM, sugeriram o uso de levantamentos gravimétricos para mapear corpos máficos e ultramáficos potencialmente portadores de mineralização.

A anomalia Bouguer é frequentemente caracterizada por uma anomalia regional ampla com variação suave, sobre a qual podem estar sobrepostos anomalias de menor comprimento de onda, chamadas de anomalias locais. Nos levantamentos terrestres de exploração, o que se deseja é obter as informações acerca dos corpos causadores das anomalias locais. $\mathrm{Na}$ análise do mapa da anomalia Bouguer já é possível notar a coerência e boa 
aplicabilidade do método gravimétrico, uma vez que os maiores valores da anomalia situam-se sobre os alvos cuja ocorrência de rochas máficas e ultramáficas já foi mapeada em superfície.

Nos perfis, os modelos indicam que os corpos dos alvos em subsuperfície estão separados e apresentam comportamentos diferentes, enquanto o corpo do alvo Lagoa da Mina na porção norte apresenta-se isolado e com largura de aproximadamente 100 metros, na porção sul o corpo de maior densidade apresenta um comportamento de dobra sinclinal em subsuperfície. $\mathrm{Na}$ porção norte os maiores teores de cobre auferidos nos testemunhos de sondagem coincidem com a localização dos corpos mais densos do modelo inverso enquanto na porção sul a ocorrência dos maiores valores está associada à bordas dos corpos mais densos o que indica que 0 processo da gênese mineral nos dois alvos ocorreram de formas diferentes. A figura 5 apresenta o comportamento da anomalia Bouguer confrontado com a dados de teor de cobre de dois furos localizados sobre o alvo lagoa da Mina na porção norte da área de estudo.
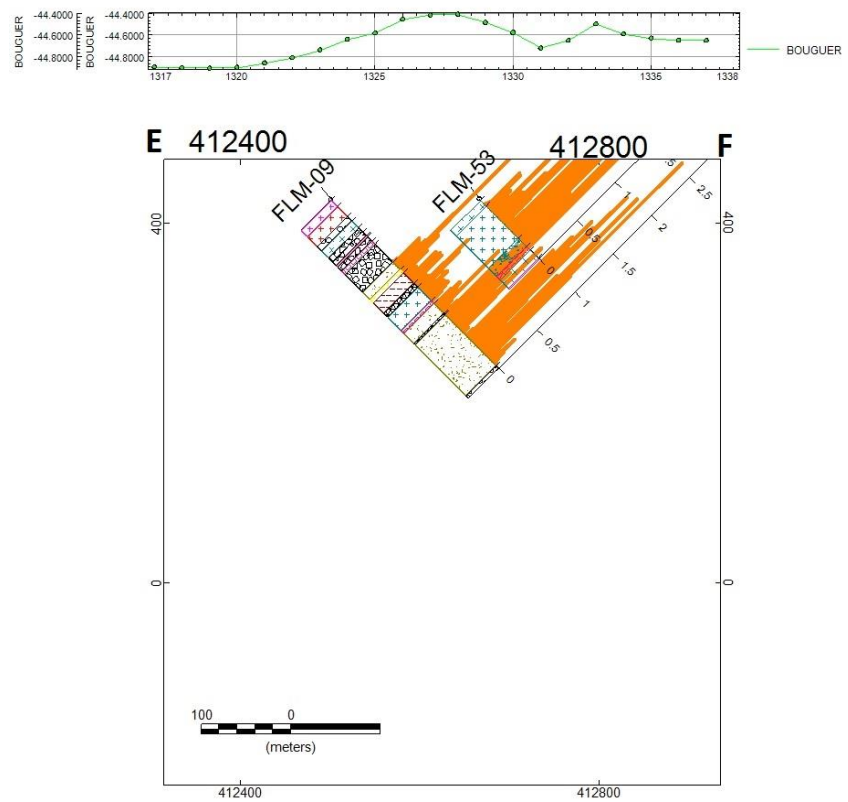

Figura 5: Perfil da anomalia Bouguer na posição 8949411 correspondente ao perfil EF do bloco tridimensional da figura 2 confrontado com dados de teor de minério de cobre nos furos FLM-09 e FLM-53.

O método gravimétrico mostrou-se eficiente no mapeamento e modelamento de corpos máficos e ultramáficos associados a depósitos de cobre no Norte da Bahia a resolução do problema gravimétrico inverso mostrou-se eficiente e uma importante ferramenta na exploração de minério de cobre em situações geológicas semelhantes à da região do trabalho.

\section{Agradecimentos}

Os autores agradecem à Mineração Caraíba S/A pela disponibilização dos dados para a realização deste trabalho

\section{Referências}

Barbosa, J. S. F., 1997. Síntese do Conhecimento Sobre a Evolução Geotectônica das Rochas Metamórficas Arqueanas e Paleoproterozóicas do Embasamento do Cráton do São Francisco na Bahia. Revista Brasileira de Geociências. Vol. 27(3):241-256.

Bello, R. M. S., 1986. Jazida de Cobre de Surubim, Vale do Curaçá, BA, Mineralogia, Petrografia e Petrogênese. Tese(doutorado) Instituto de Geociências, Universidade de São Paulo, São Paulo(SP), 458p.

Delgado, I. M e Souza, J. D. 1975. Projeto Cobre-Curaçá: Relatório Final, Geologia Econômica do Distrito Cuprífero do Rio Curaçá, Bahia, Brasil. Salvador. CPRM. 30v. $419 p$.

D'el Rey Silva L. J. H. 1984. Geologia e Controle Estrutural do Depósito Cuprífero, Vale do Curaçá, Bahia, Brasil. Dissertação (mestrado). Instituto de Geociências, Universidade Federal da Bahia. Salvador. 208p.

Farias, J. O. G., 2009. Desenvolvimento de Estudos para Elaboração do Plano Duodecenal (2010-2030) de Geologia, Mineração e Transformação Mineral. Relatório Técnico 23. Perfil da Mineração de Cobre, DNPM, Brasília(DF), 69p.

Sá, E. P., 1981. Levantamento Geofísico Integrado da Área da Terra do Sal, Curaçá, Bahia; Aplicação na Reavaliação Geológica Visando a Prospecção de Cobre, Dissertação (mestrado), UFBA, Salvador(BA), 98p. 